\title{
Electrostrictive Energy Conversion of Polyurethane with Different Hard Segment Aggregations
}

\author{
Pisan Sukwisute, ${ }^{1,2}$ Krit Koyvanitch, ${ }^{1,2}$ Chatchai Putson, ${ }^{1,2}$ and Nantakan Muensit ${ }^{1,2}$ \\ ${ }^{1}$ Department of Physics, Faculty of Science, Prince of Songkla University (PSU), Hat Yai 90112, Thailand \\ ${ }^{2}$ Center of Excellence in Nanotechnology for Energy (CENE), PSU, Hat Yai 90112, Thailand \\ Correspondence should be addressed to Nantakan Muensit; nantakan.m@psu.ac.th
}

Received 2 March 2013; Accepted 26 August 2013

Academic Editor: Shi Xue Dou

Copyright (C) 2013 Pisan Sukwisute et al. This is an open access article distributed under the Creative Commons Attribution License, which permits unrestricted use, distribution, and reproduction in any medium, provided the original work is properly cited.

\begin{abstract}
This work reported the electrostriction of polyurethane (PU) with different aggregations of hard segments (HS) controlled by dissimilar solvents: N,N-dimethylformamide (DMF) and a mixture of dimethyl sulfoxide and acetone denoted as DMSOA. By using atomic force microscopy and differential scanning calorimetry, the PU/DMSOA was observed to have larger HS domains and smoother surface when compared to those of the PU/DMF. The increase of HS domain formation led to the increase of transition temperature, enthalpy of transition, and dielectric constant $(0.1 \mathrm{~Hz})$. For the applied electric field below $4 \mathrm{MV} / \mathrm{m}$, the PU/DMSOA had higher electric-field-induced strain and it was opposite otherwise. Dielectric constant and Young's modulus for all the samples were measured. It was found that PU/DMF had less dielectric constant, leading to its lower electrostrictive coefficient at low frequency. At higher frequencies the electrostrictive coefficient was independent of the solvent type. Consequently, their figure of merit and power harvesting density were similar. However, the energy conversion was well exhibited for low frequency range and low electric field. The PU/DMSOA should, therefore, be promoted because of high vaporizing temperature of the DMSOA, good electrostriction for low frequency, and high induced strain for low applied electric field.
\end{abstract}

\section{Introduction}

Polyurethane (PU) is a versatile thermoplastic polymer, with a variety of physical and chemical electroactive properties. These properties allow PU to be used in numerous applications such as medical materials, sport goods, and coatings [1-3]. In the field of electroactive polymers, PUs are of great interest for actuation and energy conversion since they are capable of generating an electric-field-induced strain above $10 \%$ under an electric field $20 \mathrm{MV} / \mathrm{m} \mathrm{[4]} \mathrm{and} \mathrm{have} \mathrm{an}$ effective piezoelectric strain coefficient of $184 \mathrm{pC} / \mathrm{N}$ under a bias electric field of $25 \mathrm{MV} / \mathrm{m}$ comparable to that of a commercial piezoelectric PZT ceramic [5]. In addition, Guyomar and coworkers [6-9] proposed an analytical modeling based on the electrostrictive equations in order to explain the energy harvesting of PU elastomers, PU composites, and an electrostrictive poly(vinylidene fluoride-trifluoroethylenechlorofluoroethylene) terpolymer. It was found that the energy harvesting ability of these polymers increases with increasing figure of merit ( $\mathrm{FoM})$ which is related to the dielectric constant and Young's modulus. Therefore, several authors [3, 10-12] have studied and have modified structures of PU in order to control the dielectric constant and Young's modulus. Guillot and Balizer [11] reported that the electrostrictive coefficient decreases as the phase separation of HS and soft segments (SS) increase. Furthermore, the HS/SS ratio affected the electrostrictive response because the high HS contents (high polarized groups) led to the high dielectric constant, and Young's modulus [3]. Petrović et al. [10] found that PU with 50\% SS concentration, the dielectric constant, and Young's modulus depend on the degree of chemical crosslink of HS. In fact, as the HS in PU tends to form strong intermolecular hydrogen bonds, the HS will aggregate and perform as the physical cross-link in nature [13, 14]. Hence, the properties of PU can also be improved by controlling the HS aggregations through the physical cross-link.

In the present study, PU thick films with different HS aggregations controlled by different solvents were prepared. The energy conversion ability and electrostriction effect, including the dielectric constant, Young's modulus, and the electric-field-induced strain of the PUs, were comparatively 
investigated. The finding results were discussed relating mainly to HS aggregations which were identified by AFM images and DSC results.

\section{Experimental}

2.1. Materials and PU Thick Film Preparation. The available PU granules (Estane 58888 NAT 021, Lubrizol Corp.) were used in this work. This PU consisted of $4,4^{\prime}$ methylene-bis(phenyl isocyanate (MDI) and $\mathrm{BDO}$ as $\mathrm{HS}$ and poly(tetramethylene oxide) as SS. The HS content is about $46 \%$. The two types of the prepared PU thick films were designated as PU/DMF, when the N,N-dimethylformamide (DMF, 99\% purity, Sigma-Aldrich) solvent was used, and as PU/DMSOA, when the mixture of dimethyl sulfoxide (DMSO, 98\% purity, VWR International, LLC) and acetone (99.9\% purity, Fisher Scientific) was employed as a solvent. Acetone was added to the DMSO solvent in order to decrease the freezing point of DMSO, that is, $18^{\circ} \mathrm{C}$. Also, during the room temperature $\mathrm{PU}$ process volatile organic compounds would be less when using DMSO solvent.

The PU thick films were prepared through a solution casting method. $20 \mathrm{wt} . \%$ of dried PU granules were swollen either in DMF or in DMSOA mixture at $85^{\circ} \mathrm{C}$ for $2 \mathrm{~h}$ depending on the type of the PU thick films. The swollen PU was then stirred and heated until the homogeneous and sufficient vicious PU solution was obtained. Afterwards, the obtained PU solution was coated on glass plates by using the Doctor Blade film applicator with reservoir (Elcometer, France) and cured in the oven at $60^{\circ} \mathrm{C}$ for one day. After being removed from the glass plates, the films of about $80 \mu \mathrm{m}$ were annealed for $3 \mathrm{~h}$ at $125^{\circ} \mathrm{C}$ under $100 \mathrm{mbar}$ for the PU/DMSO films and under an atmosphere for PU/DMF films.

\subsection{Characterization and Measurements Techniques}

2.2.1. Atomic Force Microscopy (AFM). The free surface morphologies of the obtained PU/DMF and PU/DMSOA samples were analyzed by AFM (Nanosurf Easyscan2, Switzerland). N-type silicon probes (ACLC, Applied NanoStructures Inc., USA) were used with a nominal spring constant of 20$95 \mathrm{~N} / \mathrm{m}$ and with $225 \mu \mathrm{m}$-long cantilevers at their fundamental resonance frequencies, which varied between 145 and $230 \mathrm{kHz}$. The reflex side was coated with aluminum. The tip radius of cantilever was less than $10 \mathrm{~nm}$. The small rectangular-shaped PU samples $\left(\approx 25 \mathrm{~mm}^{2}\right)$ were mounted on a sample stage with double-sized adhesive tape and conducted to AFM measurements at room temperature operating in a tapping mode. AFM images were used for clarifying the HS aggregation in the PU samples. The HS domains appear as bright areas and the SS domains appear as dark areas [15-17].

2.2.2. Differential Scanning Calorimetry (DSC). The DSC experiments of the PU samples were carried out with a DSC 131Evo (SETARAM, USA) under liquid $\mathrm{N}_{2}$ atmosphere at scanning rate $10^{\circ} \mathrm{C} / \mathrm{min}$. All the samples were weighed approximately $22 \mathrm{mg}$ contained in closed aluminum. Thermal behaviors were investigated by heating the samples from -100 up to $200^{\circ} \mathrm{C}$ and then cooling to room temperature $\left(30^{\circ} \mathrm{C}\right)$. The midpoint of the heat capacity change was chosen to represent the glass transition temperature $\left(T_{g}\right)$, the melting temperature $\left(T_{m}\right)$ refers to the endothermic peak, and the recrystallization temperature $\left(T_{c}\right)$ can be observed from the exothermic peak. The heat of transitions $(\Delta H)$ can be calculated from endothermic or exothermic peak areas $[16$, $18]$.

2.2.3. Dielectric Property Measurement. To understand the dielectric constant $\left(\varepsilon_{r}^{\prime}\right)$ of the PU samples under an alternating electric field in a range of $10^{-1}-10^{6} \mathrm{~Hz}$ at room temperature, circular-shaped PU specimens with a diameter of $25 \mathrm{~mm}$ were cut. Gold electrodes were sputtered on both sides of all the specimens with a diameter of $20 \mathrm{~mm}$. The capacitance of each specimen was measured by the dielectric interface model 1296A (Solartron Analytical, UK). All tests were performed at an applied 1Vrms. By knowing the capacitance, thickness, and electrode areas of each specimen, the dielectric constant was derived.

2.2.4. Young's Modulus (Y) Measurement. Prior to Young's modulus measurement, all PU samples had a rectangular shape $(9 \times 12 \mathrm{~mm})$. The stress and strain of the PU samples were determined by using a uniaxial tensile setup as presented in the previous work [19]. One end of the sample was put onto a force sensor with a sensitivity of $250 \mathrm{~N} / 12 \mathrm{~V}$. The other end was clamped onto the ultraprecision linear motor moving stage (Newport corp., model XMS50, USA), which was moved in a cyclic manner. The elongation/retraction distance and the measured force of the samples were acquired on an oscilloscope (Agilent DSO7034A, France). The stress and strain of the samples were determined and as a consequence, Young's modulus of samples was derived from stress/strain ratio. This measurement was performed for small strain (2.5\%) where Hooke's law was still valid.

2.2.5. Electric-Field-Induced Strain. In all dielectric materials, electrostriction is generally defined as the quadratic coupling between the strain and polarization, or between the strain and electric field. The dielectric materials which are polarized by the electric field, the electric-field-induced strain, $S$, can be expressed as [20]

$$
S=Q P^{2}=M E^{2},
$$

where $Q$ is the charge-related electrostrictive coefficient $\left(\mathrm{m}^{4} / \mathrm{C}^{2}\right) . P$ is the polarization $\left(\mathrm{C} / \mathrm{m}^{2}\right) . M$ is the electric field related to electrostrictive coefficient $\left(\mathrm{m}^{2} / \mathrm{V}^{2}\right)$, where is equal to $Q \varepsilon_{0}^{2}\left(\varepsilon_{r}^{\prime}-1\right)^{2}$. A double-beam laser interferometer (Agilent technologies, Agilent 10889B, France) with a $10 \mathrm{~nm}$ precision was used in the experiment. The free surface sample was sandwiched between two electrodes ( $20 \mathrm{~mm}$ diameter) and the electric field was applied at low frequency $(0.1 \mathrm{~Hz})$ along the thickness direction, which was the so-called " 3 " direction. The electric-field-induced strain was measured in the same direction and hence denoted as $S_{3}$. The electric field-related electrostrictive coefficient (designated as $M_{33}$ ) was derived from a slope of fitting graph between $S_{3} / E_{3}$ and $E_{3}$. 


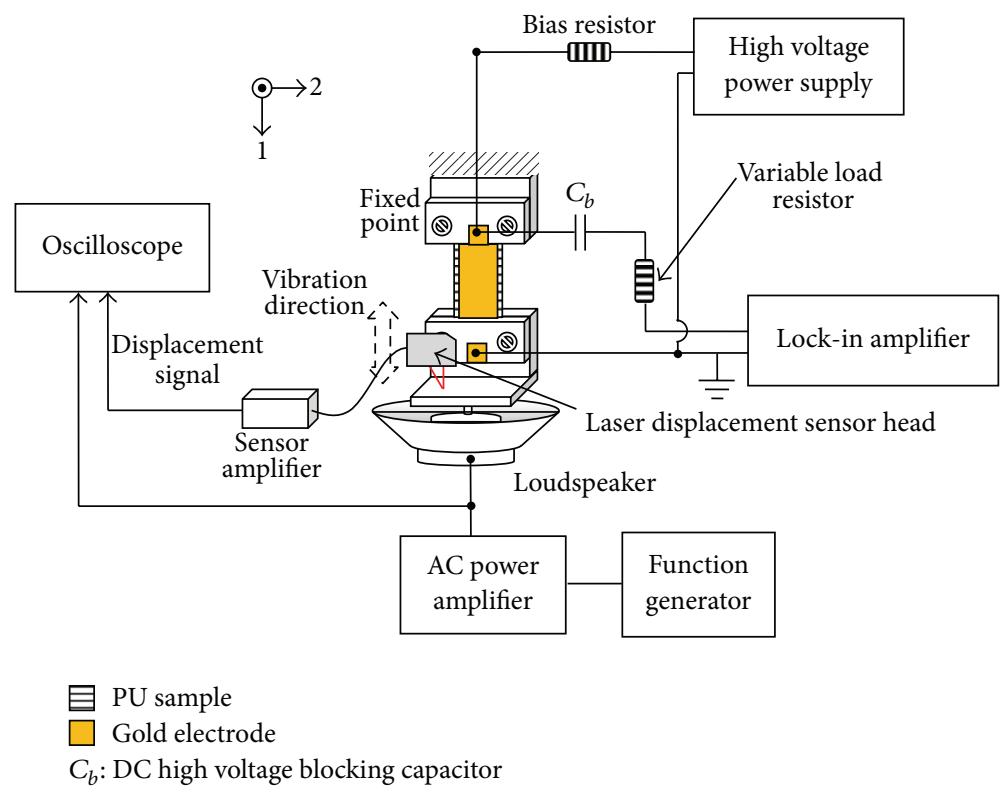

FIgURE 1: Aschematic view of the power harvesting setup.

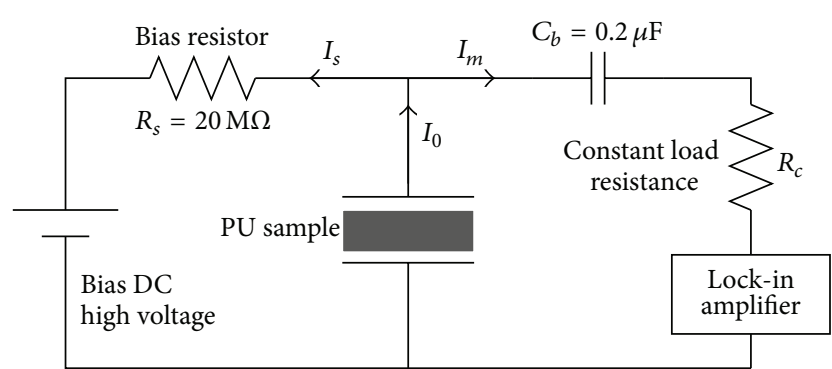

FIgURE 2: An electrical circuit connection of the power harvesting setup.

2.2.6. Energy Conversion Ability. This section aims to compare the power harvesting of the electrostrictive PU/DMF and PU/DMSOA. The power harvesting measurement was performed on a setup as shown in Figure 1. The merit of this technique is that it is easy to apply the electric field condition to the sample compared to another technique [21]. The rectangular-shaped PU sample with gold electrodes $(2 \times$ $4 \mathrm{~cm}^{2}$ ) was clamped at both ends. The upper clamped end was fixed. The other one was subjected to the loudspeaker excitation in sinusoidal form, which makes the PU sample undergo a transverse vibration (1 direction). The transverse displacement amplitude of mechanical vibration was detected by a laser displacement sensor (KEYENCE IA 030, Japan) with a precision of $1 \mu \mathrm{m}$. When the electric field and mechanical vibration were simultaneously applied to the PU sample, the ac current $\left(I_{o}\right)$ was generated. An electrical circuit connection proposed by Cottinet and coworkers [9] was shown in Figure 2. To increase the power transfer between the polymer and the electrical circuit, the values of components in the circuit were set under a condition that the current through to capacitor $\left(I_{m}\right)$ has to be much higher than the current through to biases resistor $\left(I_{s}\right)$. Therefore, $I_{m}$ was approximated to the current $I_{0}$. The constant load resistance $\left(R_{c}\right)$ was $500 \mathrm{k} \Omega$ and the $\mathrm{dc}$ bias blocking capacitor $\left(C_{b}=\right.$ $0.2 \mu \mathrm{F}$ ) filtered the dc component, thus allowing $I_{m}$ through the load $R_{c}$. The bias resistor $\left(R_{s}\right)$ provided the protection to the bias source when the polymer was shorted from break down and prevented the generated signal from leaking to the bias source. The ac power harvesting $\left(P_{\mathrm{ac}}\right)$ on the constant load resistance $R_{c}$ can be calculated through $P=I_{m}^{2} R_{c}$, where $I_{m}$ is denoted as a measured current.

As previously reported [7], for the power harvesting, the performance of this polymer depends on the FoM, which can be calculated from this relation:

$$
\text { FoM }=\frac{\left(M_{31} Y\right)^{2}}{\varepsilon_{0} \varepsilon_{r}^{\prime}},
$$

where $M_{31}$ is the electric field related to electrostrictive coefficient $\left(\mathrm{m}^{2} / \mathrm{V}^{2}\right)$. The subscript " 31 " refers to the $M$ coefficient associated with the electric field along the sample thickness (3 direction) and the strain in 1 direction. $\varepsilon_{0}$ is the permittivity of free space $\left(8.854 \times 10^{-12} \mathrm{~F} / \mathrm{m}\right)$. As previously reported [8], the $M_{31}$ value of the PU was proportional to $\left(\varepsilon_{0}\left(\varepsilon_{r}^{\prime}-1\right)^{2} / Y \varepsilon_{r}^{\prime}\right)$ and the FoM depended on the $\varepsilon_{r}^{\prime}$. Consequently, a higher FoM value exhibits a better performance of the electrostrictive PU in transforming ambient mechanical energy into the electric energy.

\section{Results and Discussion}

3.1. AFM Images. The surface topologies of the PU/DMF and PU/DMSOA samples were analyzed with AFM in the tapping mode. The two surface topologies of the samples are shown in Figure 3. Theses topographic images suggest that the PU composed of HS domains arises from packing of HS, that 


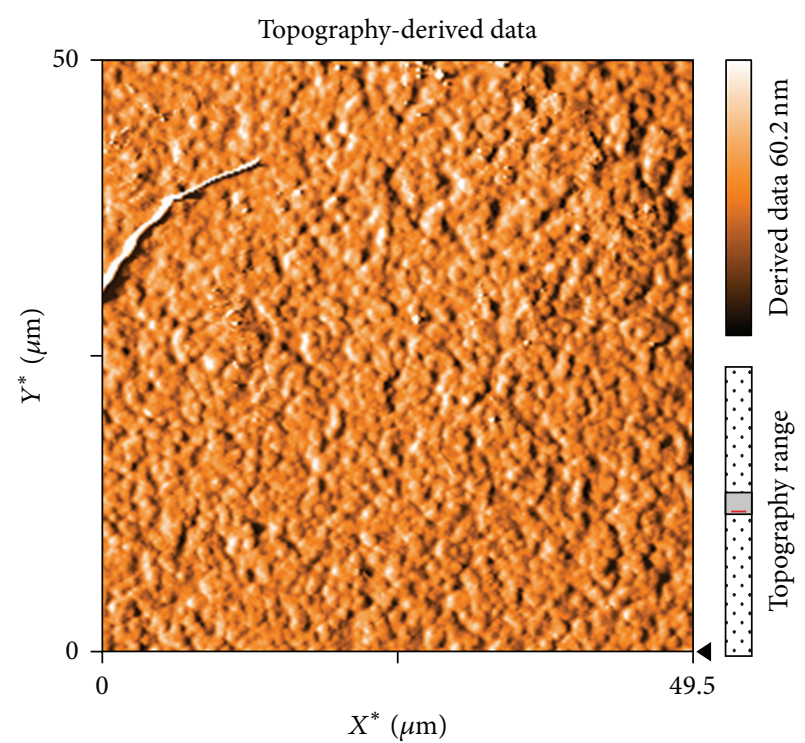

(a)

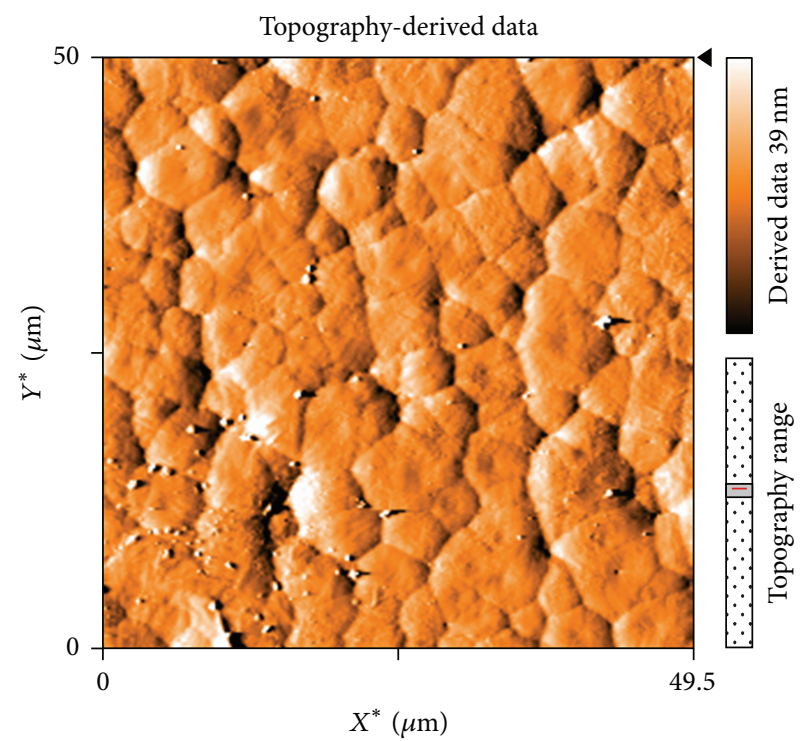

(c)

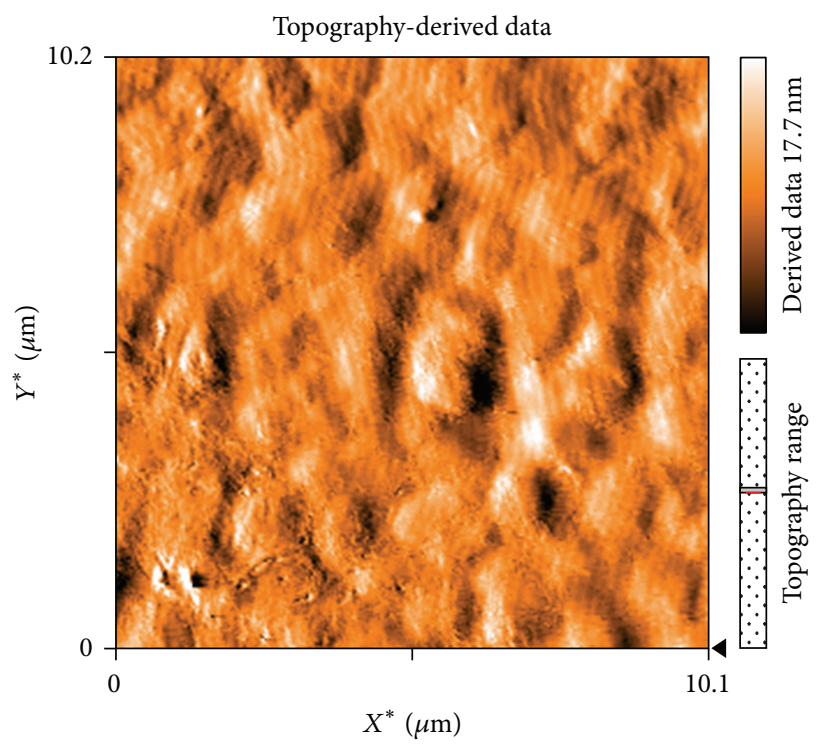

(b)

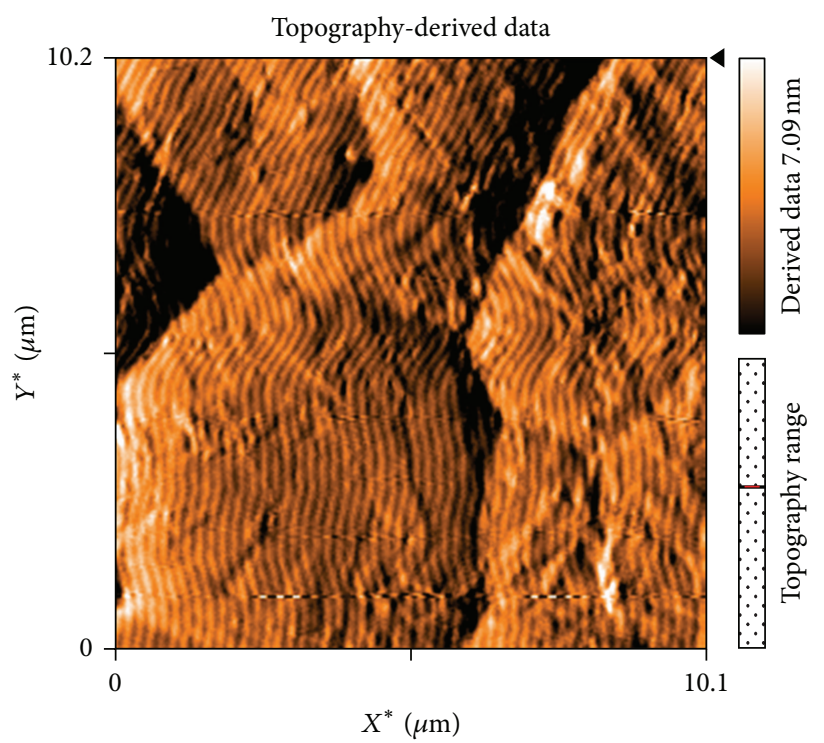

(d)

Figure 3: AFM topographic images of the free surfaces of (a, b) PU/DMF and (c, d) PU/DMSOA. All images are obtained from scanning rate at $1 \mathrm{~s} /$ line and 250 points/line.

is, HS aggregation. The HS aggregation was raised due to the fact that the HS (urethane groups) in the PU tend to form strong hydrogen bond between each other and act as the physical cross-links. An increase of the hydrogen bond formation results in an increase of HS ordering domains (HS domain organization) and microdomain separation $[13,14]$. Considering Figures 3(a) and 3(c), it was found that the HS domains in the PU/DMSOA were larger than those in the PU/DMF. The HS domains in the PU/DMSOA (Figure 3(c)) were nonuniform and varied from 2 to $8 \mu \mathrm{m}$. Figure $3(\mathrm{~b})$ presents the enlargement of Figure 3(a). It can be seen that HS domain boundaries of the PU/DMF are unclear, and HS domain is approximately $1 \mu \mathrm{m}$. Therefore, it can be concluded that the HS aggregations in PU/DMSOA were higher than that in the PU/DMF sample. This was because the DMSO had effectively induced the HS aggregation during the thermal treatment process. It is possible that DMSO is able to form two hydrogen bonds and act as the cross-link agent, while DMF would be able to form only one hydrogen bond [22]. The root mean square (rms) surface roughness of the PU/DMF and PU/DMSOA estimated from Figures 3(a) and 3(c) was about 10 and $6 \mathrm{~nm}$, respectively. Thus, the HS aggregations also affected a surface roughness of the samples. A great HS segment aggregations led to the smoother surface of the samples.

3.2. DSC Analysis. Many authors suggest that the DSC experiment provides information on the thermodynamic behavior of PU associated with microdomain purity or microdomain separation degree, that is, the existence of HS in 
TABLE 1: DSC thermal data of polyurethane samples dissolved in different solvents.

\begin{tabular}{lcccccccc}
\hline Sample & ${ }^{\mathrm{a}} T_{g 1}\left({ }^{\circ} \mathrm{C}\right)$ & ${ }^{\mathrm{a}} T_{g 2}\left({ }^{\circ} \mathrm{C}\right)$ & ${ }^{\mathrm{b}} T_{m 1}\left({ }^{\circ} \mathrm{C}\right)$ & ${ }^{\mathrm{c}} T_{\text {MMT }}\left({ }^{\circ} \mathrm{C}\right)$ & ${ }^{\mathrm{b}} T_{m 2}\left({ }^{\circ} \mathrm{C}\right)$ & ${ }^{\mathrm{d}} \Delta H_{f}(\mathrm{~J} / \mathrm{g})$ & ${ }^{\mathrm{e}} T_{c}\left({ }^{\circ} \mathrm{C}\right)$ & ${ }^{\mathrm{f}} \Delta H_{c}(\mathrm{~J} / \mathrm{g})$ \\
\hline PU/DMF & -49.8 & - & - & 148.2 & 173.4 & 08.91 & 089.0 \\
PU/DMSOA & -52.3 & -25.4 & 136.6 & 163.4 & 177.1 & 11.83 & 143.7 & -16.13 \\
\hline
\end{tabular}

alass transition temperature $\left({ }^{\circ} \mathrm{C}\right)$.

${ }^{\mathrm{b}}$ melting temperature $\left({ }^{\circ} \mathrm{C}\right)$.

${ }^{\mathrm{c}}$ microphase mixing transition (MMT) temperature $\left({ }^{\circ} \mathrm{C}\right)$.

$\mathrm{d}$ enthalpy of melting $(\mathrm{J} / \mathrm{g})$.

${ }^{\mathrm{e}}$ recrytallization temperature $\left({ }^{\circ} \mathrm{C}\right)$.

$\mathrm{f}$ enthalpy of recrystallization $(\mathrm{J} / \mathrm{g})$.

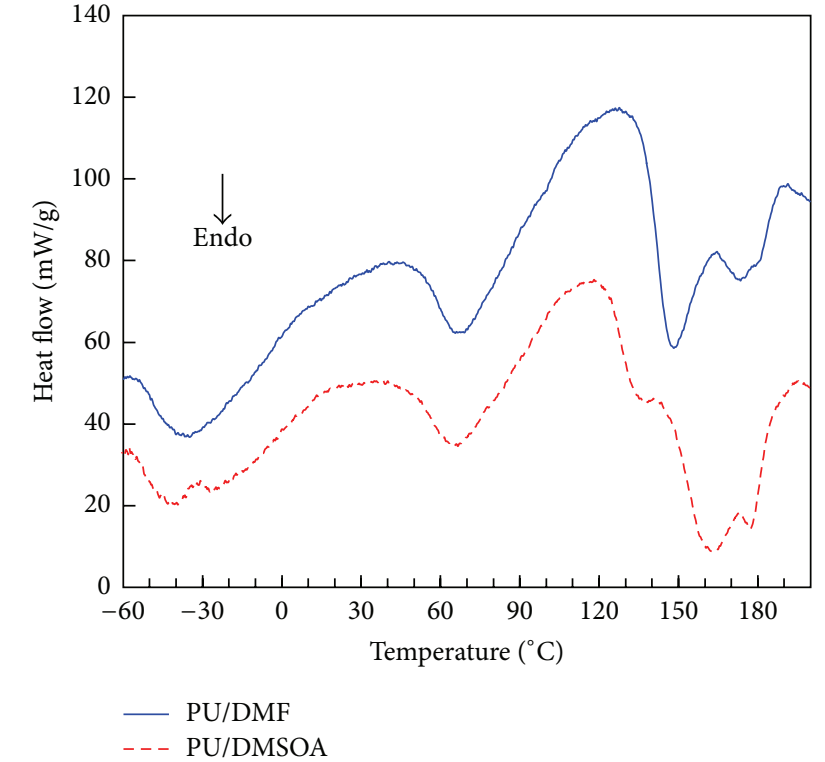

FIGURE 4: DSC endothermic thermograms of the PU/DMF and PU/ DMSOA samples.

SS [16, 23-26]. First of all, in order to understand thermal transition of PU, we must consider that the chemical structure and composition of the obtained PU films in this work are similar because only one type of the PU was used. Therefore, the HS aggregations depend on the synthesis conditions and thermal treatment history of the samples and thermal transition of the samples can be only ascribed to the presence of the physical cross-links. DSC thermograms of the PU/DMF and PU/DMSOA samples used to obtain the AFM images are shown in Figure 3. A summary of the thermal transitions is listed in Table 1.

As a previous investigation [23] mentioned the glass transition temperature $\left(T_{g}\right)$ values expose the relative purity of the soft domain. $T_{g}$ of PU is raised when $\mathrm{HS}$ are dissolved in the SS domain and leads to a decreasing in degree of phase separation, that is, the increase of the partial phase mixing. In the thermogram, Figure 4, PU/DMF and PU/DMSOA show the value of $T_{g 1}$ at approximately $-50^{\circ} \mathrm{C}$, referred to as glass transition of SS domain. Regarding the case of PU/DMSOA, the unlikely $T_{g 2}\left(-25.4^{\circ} \mathrm{C}\right)$ can be observed. This probably corresponds to the formation of heterogeneous mixed phases arising from nonuniform HS aggregations dissolving in the soft domain as presented in Figure 3(c).

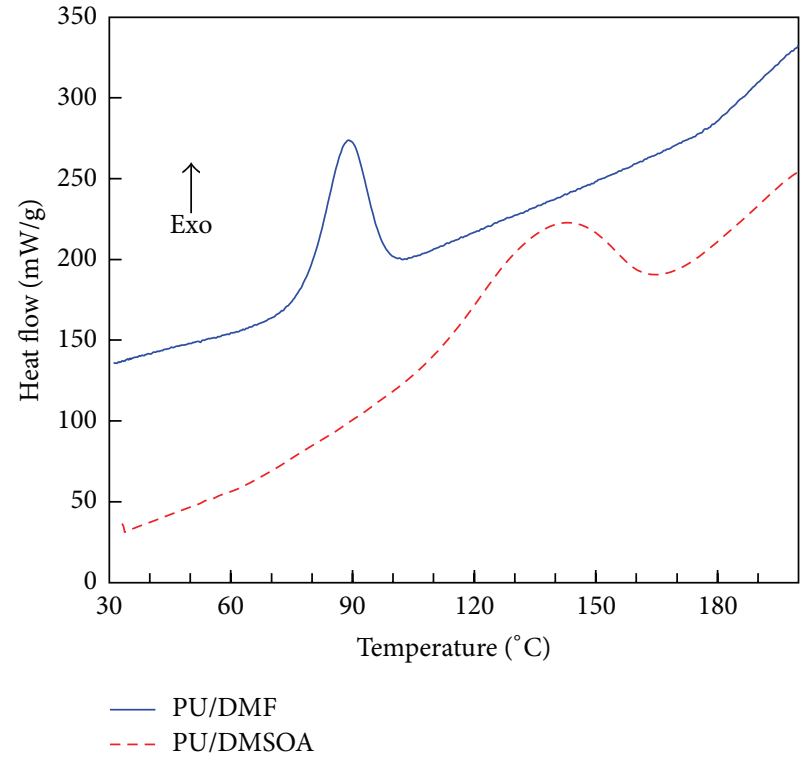

FIGURE 5: DSC exothermic thermograms of the PU/DMF and PU/ DMSOA samples.

Figure 4 also shows the endothermic peaks near $67^{\circ} \mathrm{C}$ for both samples. This endotherm is related to some relaxation effects of the polymer chains in the HS domain [25, 26]. Next, multiple endothermic peaks appearing in an interval of $130^{\circ} \mathrm{C}$ to $180^{\circ} \mathrm{C}$ confirmed the nonuniform HS domain size in the PU samples. There are 3 different mechanisms involved: first, a melt temperature of short range ordering HS domain denoted as $T_{m 1}$, second, a process of either segregation of long range ordering HS domain or a transition temperature related to the separation of HS and SS (designated as $T_{\mathrm{MMT}}$ ), and finally, the melt temperature of long range ordering HS domain $\left(T_{m 2}\right)$. Regarding the $T_{m 1} . T_{\text {MMT }}$ and $T_{m 2}$ values in Table 1, it can be attributed to the fact that each sample still has the different ordering HS domain, that is, different HS aggregations. The higher values of the $T_{\mathrm{MMT}}$ and $T_{m 2}$ indicated that the HS aggregations in the PU/DMSOA were greater. Furthermore, the $\Delta H_{f}$ value of PU/DMSOA are higher than those of PU/DMF due to the larger HS aggregation in the HS domain. Similarly, the higher $T_{c}$ and the enthalpy of recrystallization $\left(\Delta H_{c}\right)$ for exothermic behavior of the PU/DMSOA sample in Figure 5 also suggested that this sample had the larger crystallization arising from the higher 


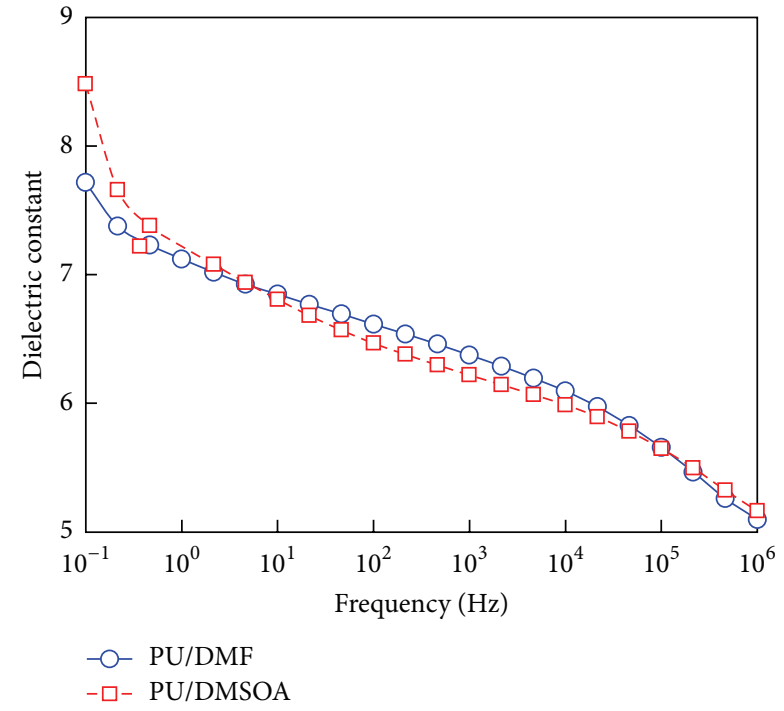

FIgURE 6: Values of the dielectric constant of the PU/DMF and PU/ DMSOA samples as a function of frequency.

HS aggregations. Therefore, the DSC results help to confirm the existence of the HS aggregations.

3.3. Dielectric Constant. According to previous reports [11, 12], PU consists of the rubbery SS and polar HS. The HS tend to aggregate together and control the dielectric property of PU. Therefore, if the HS domains are large, the higher dielectric value can be observed. Figure 6 shows the dielectric constant of PU/DMF and PU/DMSOA. Considering a frequency range lower than $4 \mathrm{~Hz}$, the dielectric constant increases with decreasing frequency. PU/DMSOA exhibits higher dielectric constant than that of PU/DMF owing to its larger HS domains. This leads to its greater polarization. For the other range of frequency, the dielectric constant of both PU/DMF and PU/DMSOA became similar values and decreased with raising the frequency.

3.4. Electric-Field-Induced Strain. Figure 7(a) shows the electric-field-induced strain versus the applied electric field. When the applied electric field was less than $4 \mathrm{MV} / \mathrm{m}$, the electric-field-induced strain was a quadratic curve. The PU/DMSOA had higher electric-field-induced strain than PU/DMF due to its electrostriction effect. After the quadratic curve, plateau saturation strain was observed. PU/DMF had higher plateau saturation strain than PU/DMSOA due to its saturation of dipole moment in heterogeneous PU matrix and HS domain mobility. For further explanations, as previously reported [4], the dielectric constant reached its saturation and the increase of the compressive stress versus electrical field led to an increase of the polymer rigidity and consequently to an increase of Young's modulus. In addition, under the increase of compressive stress, mobility of HS domains decreased with raising its size. Therefore, the combination of these effects caused the lower plateau saturation strain in PU/DMSOA.

Within the quadratic curve, although the dielectric constant increases with increasing the electric field, the increase of

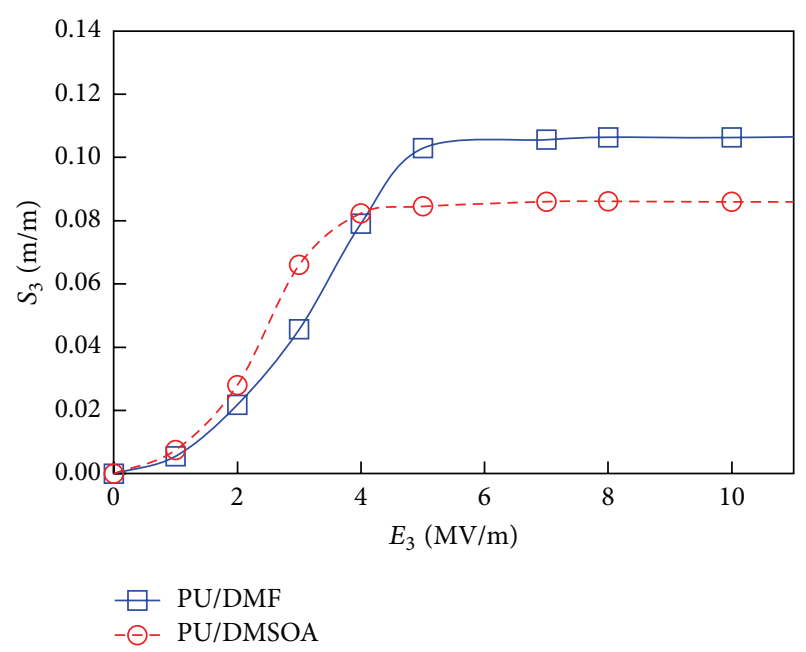

(a)

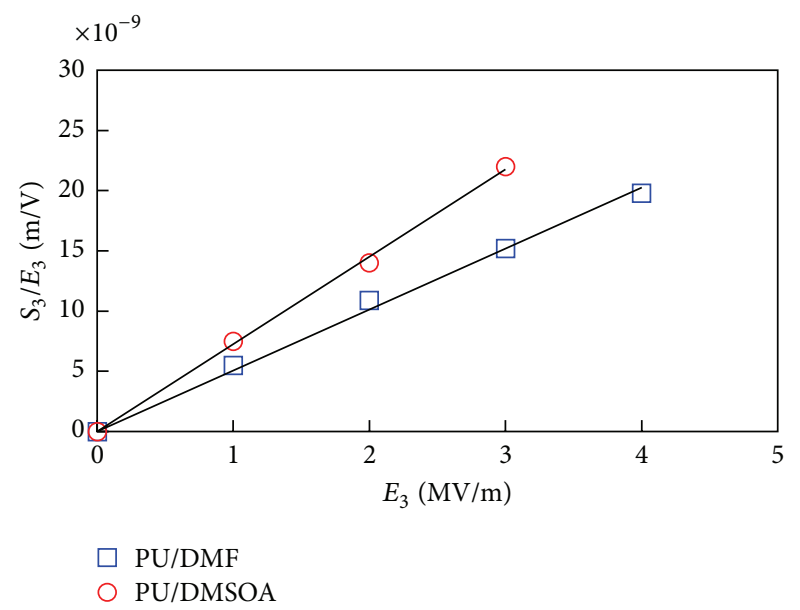

(b)

Figure 7: (a) Variations of the electric-field-induced strain versus electric field for the PU/DMF and PU/DMSOA samples. (b) Ratios of the electric-field-induced strain to electric field $\left(S_{3} / E_{3}\right)$ varied with electric fields for the PU/DMF and PU/DMSOA samples.

TABLE 2: Young's modulus, dielectric constant $\left(\varepsilon_{r}^{\prime}\right), M_{31}$ coefficient, and FoM of the PU/DMF and PU/DMSO samples.

\begin{tabular}{lcccc}
\hline Sample & $\begin{array}{c}Y \\
(\mathrm{MPa})\end{array}$ & $\begin{array}{c}\varepsilon_{r}^{\prime} \\
(\text { at } 20 \mathrm{~Hz})\end{array}$ & $\begin{array}{c}-M_{31} \\
\left(\mathrm{~m}^{2} / \mathrm{V}^{2}\right)\end{array}$ & $\begin{array}{c}\text { FoM } \\
\left(\mathrm{N}^{2} \mathrm{~m}^{3} / \mathrm{V}^{4} \cdot \mathrm{F}\right)\end{array}$ \\
\hline PU/DMF & 25.3 & 6.77 & $1.7 \times 10^{-18}$ & $3.2 \times 10^{-11}$ \\
PU/DMSOA & 26.5 & 6.68 & $1.6 \times 10^{-18}$ & $3.1 \times 10^{-11}$ \\
\hline
\end{tabular}

this was inferior for the low electric field and the electrostriction effect became dominant. Thus, linear character between $S_{3} / E_{3}$ and $E_{3}$ can be observed as shown in Figure 7(b). An increase in the slope refers to the increase of $M_{33}$ coefficient. The larger $M_{33}$ can be obtained from PU/DMSOA thanks to its higher dielectric constant.

3.5. Energy Conversion Ability. Table 2 summarizes the values of Young's modulus, the dielectric constant, the $M_{31}$ coefficient, and FoM obtained from the theoretical calculation 


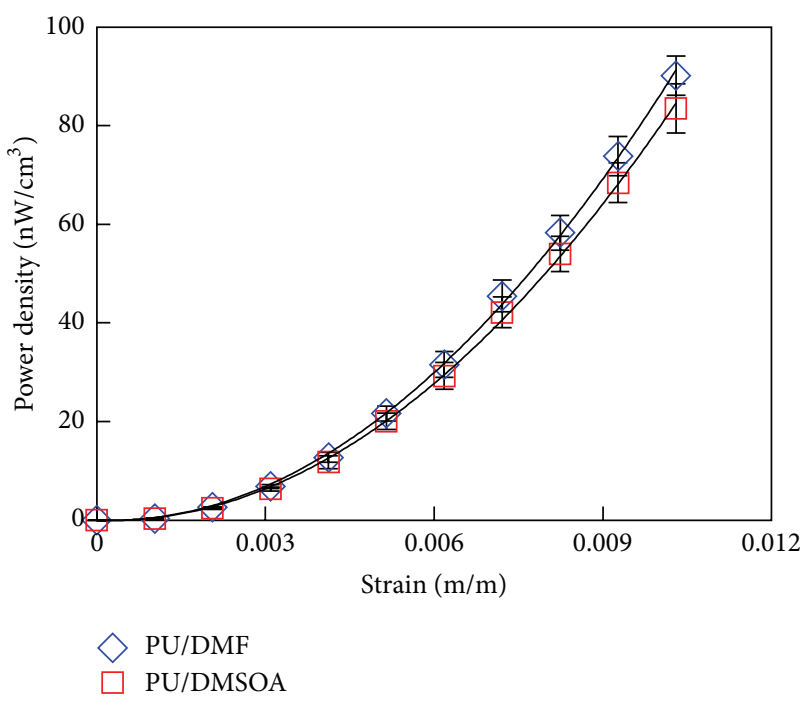

FIGURE 8: The power harvesting density as a function of the strain magnitude for the PU/DMF and PU/DMSOA samples measured at $20 \mathrm{~Hz}, 3 \mathrm{MV} / \mathrm{m}$, and $500 \mathrm{k} \Omega$.

for PU/DMF and PU/DMSOA at frequency of $20 \mathrm{~Hz}$. It can be observed that there is no significant difference in the dielectric constant and Young's modulus for both samples. This, as a result, leads to the similarity in the values of the $M_{31}$ coefficients and FoM of the PU/DMF and PU/DMSOA. Figure 8 shows that the power harvesting density $\left(P_{h}\right)$ exhibits a quadratic dependence with the strain of all the samples. With measurement error up to $5 \%$ taken into account, the differences in HS aggregations caused by different solvents did not distinguishably affect the power harvesting density of the PUs.

\section{Conclusions}

The studied electrostrictive PUs dissolved in DMSOA and DMF showed the difference in HS aggregations. Larger HS domains caused by the HS aggregations and smoother surface were observed for the PU/DMSOA. This indicates that DMSOA solvent effectively induced the HS formation. The increase of HS domain formation led to the increase of transition temperature, enthalpy of transition, and dielectric constant observed at low frequency $(0.1 \mathrm{~Hz})$. Consequently, the electric-field-induced strain was raised in a range of low electric field. At higher frequency, the PUs did not show significant difference in the dielectric constant, Young's modulus, and FoM values. The differences in HS aggregations, thus, did not affect the power harvesting ability.

\section{Acknowledgments}

This work was financially supported by the Thailand Research Fund through the Royal Golden Jubilee Ph.D. Program under Grant no. PHD/0189/2551 and the Franco-Thai Joint Research Project under the Partenariat Hubert Curien (PHC) Program
(Grant no. 20591ZL). The authors deeply thank D. Guyomar and $\mathrm{M}$. Lallart for valuable suggestions.

\section{References}

[1] K. Hayashida, K. Kanda, H. Yaku, J. Ando, and Y. Nakayama, "Development of an in vivo tissue-engineered, autologous heart valve (the biovalve): preparation of a prototype model," Journal of Thoracic and Cardiovascular Surgery, vol. 134, no. 1, pp. 152159, 2007.

[2] E.-H. Kim, W.-R. Lee, S.-W. Myoung et al., "Characterization of waterborne polyurethane for ecofriendly functional floor plate," Progress in Organic Coatings, vol. 67, no. 2, pp. 102-106, 2010.

[3] N.-J. Jo, D.-H. Lim, G.-M. Bark, H.-H. Chun, I.-W. Lee, and H. Park, "Polyurethane-based actuators with various polyols," Journal of Materials Science and Technology, vol. 26, no. 8, pp. 763-768, 2010.

[4] D. Guyomar, P.-J. Cottinet, L. Lebrun et al., "The compressive electrical field electrostrictive coefficient M33 of electroactive polymer composites and its saturation versus electrical field, polymer thickness, frequency, and fillers," Polymers for Advanced Technologies, vol. 23, no. 6, pp. 946-950, 2012.

[5] R. Liu, Q. Zhang, and L. E. Cross, "Experimental investigation of electrostrictive polarization biased direct apparent piezoelectric properties in polyurethane elastomer under quasistatic conditions," Journal of Applied Polymer Science, vol. 73, pp. 26032609, 1999.

[6] D. Guyomar, L. Lebrun, C. Putson, P.-J. Cottinet, B. Guiffard, and S. Muensit, "Electrostrictive energy conversion in polyurethane nanocomposites," Journal of Applied Physics, vol. 106, no. 1, Article ID 014910, 2009.

[7] C. Putson, L. Lebrun, D. Guyomar et al., "Effects of copper filler sizes on the dielectric properties and the energy harvesting capability of nonpercolated polyurethane composites," Journal of Applied Physics, vol. 109, no. 2, Article ID 024104, 2011.

[8] L. Lebrun, D. Guyomar, B. Guiffard, P.-J. Cottinet, and C. Putson, "The Characterisation of the harvesting capabilities of an electrostrictive polymer composite," Sensors and Actuators A, vol. 153, no. 2, pp. 251-257, 2009.

[9] P.-J. Cottinet, M. Lallart, D. Guyomar et al., "Analysis of acdc conversion for energy harvesting using an electrostrictive polymer P(VDF-TrFE-CFE)," IEEE Transactions on Ultrasonics, Ferroelectrics, and Frequency Control, vol. 58, no. 1, pp. 30-42, 2011.

[10] Z. S. Petrović, I. Javni, and G. Bánhegy, "Mechanical and dielectric properties of segmented polyurethane elastomers containing chemical crosslinks in the hard segment," Journal of Polymer Science B, vol. 36, no. 2, pp. 237-251, 1998.

[11] F. M. Guillot and E. Balizer, "Electrostrictive effect in polyurethanes," Journal of Applied Polymer Science, vol. 89, no. 2, pp. 399-404, 2003.

[12] S. Oprea, "Effect of the hard-segment structure on the dielectric relaxation of crosslinked polyurethanes," Journal of Applied Polymer Science, vol. 119, no. 4, pp. 2196-2204, 2011.

[13] Y. M. Tsai, T. L. Yu, and Y. H. Tseng, "Physical properties of crosslinked polyurethane," Polymer International, vol. 47, pp. 445-450, 1998.

[14] T.-T. Hsieh, K.-H. Hsieh, G. P. Simon, C. Tiu, and H.-P. Hsu, "Effect of crosslinking density on the physical properties of interpenetrating polymer networks of polyurethane and 2-hydroxyethyl methacrylate-teminated polyurethane," Journal of Polymer Research, vol. 5, no. 3, pp. 153-162, 1998. 
[15] R. S. McLean and B. B. Sauer, "Tapping-mode AFM studies using phase detection for resolution of nanophases in segmented polyurethanes and other block copolymers," Macromolecules, vol. 30, no. 26, pp. 8314-8317, 1997.

[16] A. Eceiza, M. Larrañaga, K. de la Caba et al., "Structure-property relationships of thermoplastic polyurethane elastomers based on polycarbonate diols," Journal of Applied Polymer Science, vol. 108, no. 5, pp. 3092-3103, 2008.

[17] B. B. Sauer, R. S. Mclean, R. J. Gaymans, and M. C. J. E. Niesten, "Crystalline morphologies in segmented copolymers with hard segments of uniform length," Journal of Polymer Science B, vol. 42, no. 9, pp. 1783-1792, 2004.

[18] J. D. Menczel and R. B. Prime, Thermal Analysis of Polymers: Fundamentals and Applications, John Wiley and Sons, Hoboken, NJ, USA, 2009.

[19] J. Galineau, B. Guiffard, L. Seveyrat, M. Lallart, and D. Guyomar, "Study and modeling of an electrostrictive polyurethane diaphragm loaded with conductive carbon black," Sensors and Actuators A, vol. 189, pp. 117-124, 2013.

[20] K. Wongtimnoi, B. Guiffard, A. Bogner-Van de Moortèle, L. Seveyrat, C. Gauthier, and J.-Y. Cavaillé, "Improvement of electrostrictive properties of a polyether-based polyurethane elastomer filled with conductive carbon black," Composites Science and Technology, vol. 71, no. 6, pp. 885-892, 2011.

[21] Y. Liu, K. L. Ren, H. F. Hofmann, and Q. Zhang, "Investigation of electrostrictive polymers for energy harvesting," IEEE Transactions on Ultrasonics, Ferroelectrics, and Frequency Control, vol. 52, no. 12, pp. 2411-2417, 2005.

[22] C. L. de Vasconcelos, R. R. Martins, M. O. Ferreira, M. R. Pereira, and J. L. C. Fonseca, "Rheology of polyurethane solutions with different solvents," Polymer International, vol. 51, no. 1, pp. 69-74, 2002.

[23] A. Eceiza, M. D. Martin, K. De La Caba et al., “Thermoplastic polyurethane elastomers based on polycarbonate diols with different soft segment molecular weight and chemical structure: mechanical and thermal properties," Polymer Engineering and Science, vol. 48, no. 2, pp. 297-306, 2008.

[24] A. Saiani, W. A. Daunch, H. Verbeke, J.-W. Leenslag, and J. S. Higgins, "Origin of multiple melting endotherms in a high hard block content polyurethane. 1: thermodynamic investigation," Macromolecules, vol. 34, no. 26, pp. 9059-9068, 2001.

[25] A. Lapprand, F. Méchin, and J.-P. Pascault, "Synthesis and properties of self-crosslinkable thermoplastic polyurethanes," Journal of Applied Polymer Science, vol. 105, no. 1, pp. 99-113, 2007.

[26] T. K. Chen, T. S. Shieh, and J. Y. Chui, "Studies on the first DSC endotherm of polyurethane hard segment based on 4,4'-diphenylmethane diisocyanate and 1,4-butanediol," Macromolecules, vol. 31, no. 4, pp. 1312-1320, 1998. 

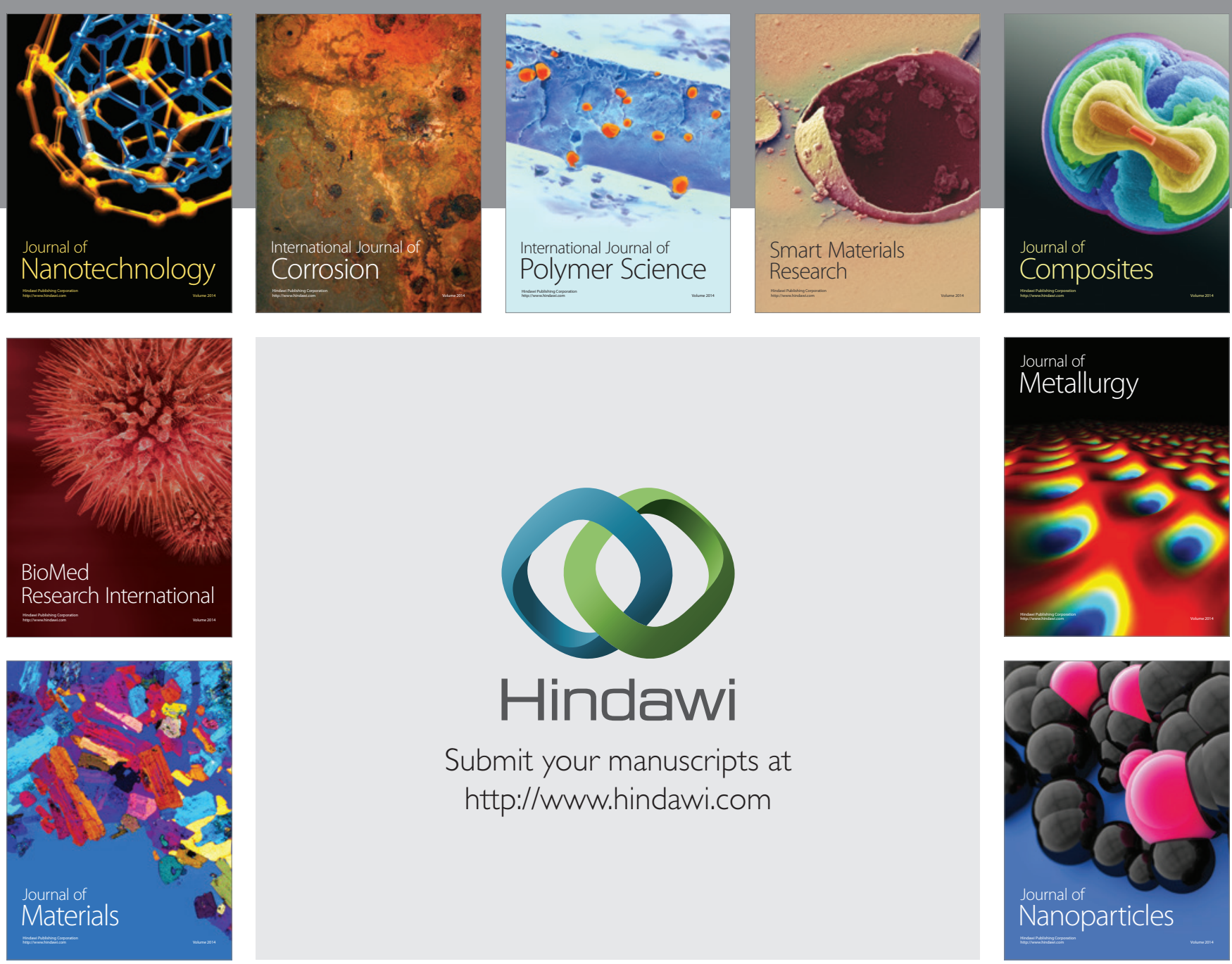

Submit your manuscripts at http://www.hindawi.com
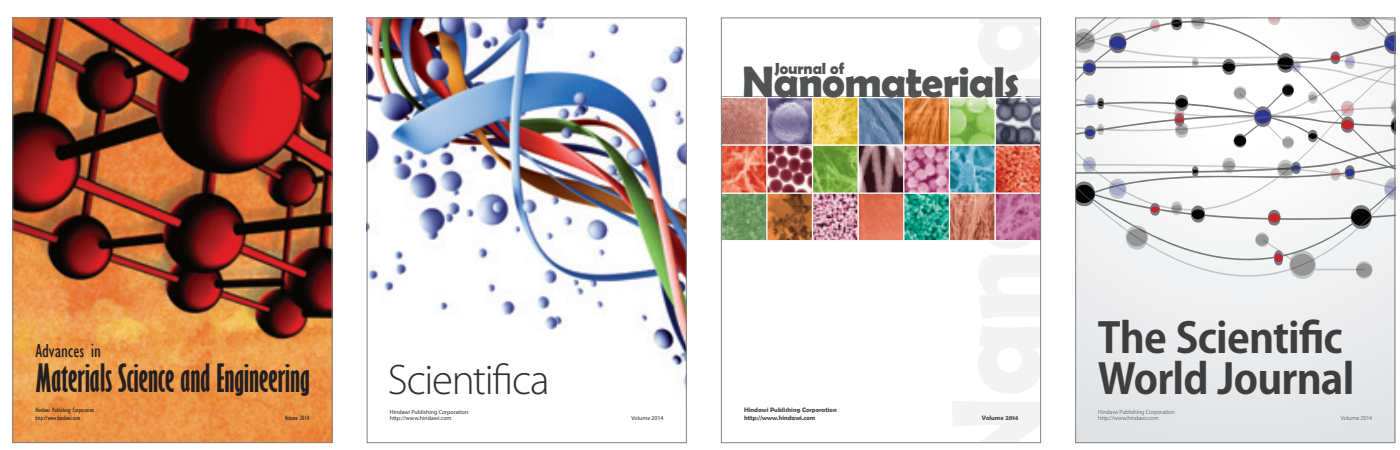

\section{The Scientific World Journal}
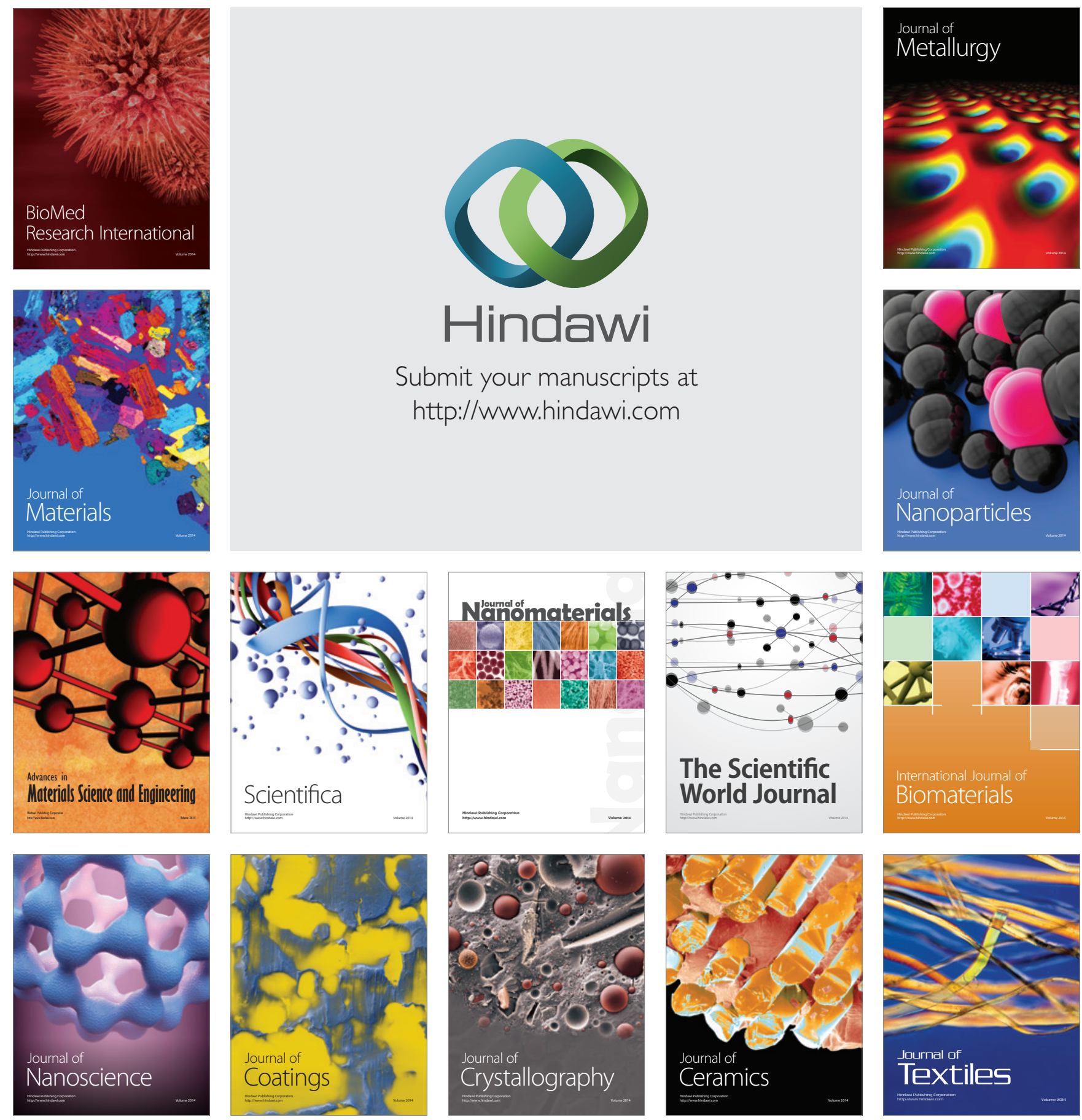